\title{
Para la adecuada inclusión de los psicólogos clínicos en el vigente estatuto jurídico del personal estatutario del Insalud
}

El vigente estatuto jurídico del personal que presta sus servicios en el INSALUD, resulta ser en la actualidad norma de importante significación por cuanto define los derechos y obligaciones del mismo, regulando a cada colectivo profesional básicamente en función de los distintos grupos profesionales, funciones desempeñadas y ubicación en el sistema.

La ampliamente reconocida obsolescencia de esta norma -preconstitucional- de ya larga existencia para dar cuenta de las nuevas situaciones existentes, ha impulsado distintos proyectos para una nueva regulación, de la que son frutos los distintos borradores existentes para promulgar en un -esperemos que breve- futuro el nuevo Estatuto-Marco de Personal de los servicios de salud.

La existencia de una específica regulación para el personal de los servicios sanitarios se ha mantenido, incluso tras la Ley 30/1984 de Medidas de Reforma para la Función Pública, que tuvo como uno de sus principales objetivos la unificación de los distintos regímenes de personal hasta entonces existentes. De hecho, la Disposición Transitoria Cuarta de dicha Ley, abre el compromiso de elaborar una normativa especial para el personal estatutario.

El Estatuto Básico de la Función Pública expone la necesidad de una normativa específica para el personal sanitario de las instituciones del Sistema Nacional de Salud (SNS), y en su Disposición Adicional Séptima establece la obligatoriedad de elaborar el Estatuto-Marco que habrá de establecer las bases del régimen de este personal, considerando las características de la práctica de las profesiones sanitarias, de las prestaciones asistenciales y del propio Sistema Nacional de Salud.

Asimismo, la Ley General de Sanidad en su artículo 84 estableció que un EstatutoMarco regularía al personal estatutario de los Servicios de Salud.

Por tanto, el futuro Estatuto-Marco no sólo dará cuenta de una tradición sostenida históricamente, sino que parece existir un amplio consenso acerca del carácter de su necesidad para este peculiar servicio público, lo que la vigente legislación antes reseñada asimismo recoge.

La organización política, territorial y competencial del Estado en las Comunidades Rev. Asoc. Esp. Neuropsiq., 2000, vol XX, n. ${ }^{\circ} 76$, pp. 103-105 
Autónomas, establecido por la Constitución y en aplicación de la Ley General de Sanidad, conduce a la organización progresiva del Sistema Nacional de Salud concebido como el conjunto de los Servicios de Salud, con un funcionamiento coordinado, función cuya máxima expresión queda atribuida al Estado. El nuevo Estatuto-Marco habrá de evitar el menoscabo de las peculiaridades de cada territorio del Estado, sus competencias y la organización de los servicios sanitarios.

La entrada en vigor de un nuevo Estatuto-Marco derogaría los tres Estatutos de Personal de las Instituciones Sanitarias de la Seguridad Social (el del personal medicofacultativo, el del personal sanitario no facultativo y el del personal no sanitario), que configuran el cuerpo central del vigente Estatuto Jurídico, así como de las disposiciones que los completaron.

Por tanto, la trascendencia del vigente Estatuto Jurídico, como del futuro EstatutoMarco resulta evidente para el Sistema Nacional de Salud y para la ubicación adecuada y funcional de los colectivos profesionales en el mismo.

En la actualidad y desde hace años se sostiene en el INSALUD una disfuncional, desafortunada, injusta e irregular ubicación de los psicólogos, a los que se sitúa fuera del Estatuto del Personal Médico de la Seguridad Social, excluyendo así el reconocimiento del obvio carácter sanitario de sus prestaciones.

El Real Decreto 2490 de creación de la especialidad de Psicología Clínica, de 20 de Noviembre de 1998, establece explícitamente la necesidad de incluirlos en dicho estatuto vigente, tal y como lo han venido siendo aquellos colectivos que han alcanzado la creación -y regulación- de la especialidad sanitaria de disciplinas no médicas.

No obstante hasta la fecha esto no ha sido así.

La existencia de proyectos sucesivos para un nuevo Estatuto-Marco futuro, de ninguna manera justifica esta demora que, además de evidentes perjuicios a estos profesionales y a la ubicación de esta especialidad como sanitaria en el INSALUD, conlleva una situación de ambigüedad en los alcances del carácter de las prestaciones de los psicólogos a los ciudadanos que acceden al INSALUD, lo que redunda en un evidente perjuicio para los mismos.

Conscientes de todo ello, la Asociación Española de Neuropsiquiatría y la Asociación Española de Psicología Clínica y Psicopatología acordaron la elaboración del presente documento, que recoge la posición de ambas asociaciones ante este problema, cuya solución viene ya articulada por el Real decreto de creación de la Especialidad.

La aplicación del citado Real Decreto establece la inclusión inmediata de los psicólogos clínicos en el vigente Estatuto Jurídico del Personal Medico de la Seguridad Social. 
INFORMES

Para ello en el capitulo I, que se refiere al personal comprendido, Articulo $1^{\circ}$, relativo al ámbito de aplicación se deberá añadir:

La disposición adicional segunda del Decreto de la Especialidad en Psicología Clínica, relativa a la normativa aplicable al personal estatutario que dice:

"El personal estatutario que, estando en posesión del titulo oficial de Psicólogo Especialista en Psicología Clínica, preste servicio en Instituciones Sanitarias de la Seguridad Social, en puestos de trabajo que requieran los conocimientos inherentes a dicho titulo, estará incluido en el ámbito de aplicación del Estatuto Jurídico de Personal Medico de la Seguridad Social al que accederá por el procedimiento establecido para los facultativos especialistas".

Como ya se ha hecho con anterioridad con otras especialidades sanitarias de nueva creación.

De esta forma los psicólogos clínicos estarán reconocidos como facultativos especialistas, quedando sujetos como tal a los derechos y obligaciones inherentes al citado estatuto.

Asimismo desarrollarán las funciones correspondientes a los facultativos especialistas señaladas en el capitulo III, del citado estatuto, relativo a los deberes, articulo 23 , que desarrolla las funciones de los especialistas, y de acuerdo con la normativa del funcionamiento de las unidades de salud mental, publicada por Insalud en 1986.

En segundo lugar queremos hacer también algunas observaciones referidas al futuro Estatuto-Marco del Personal de los servicios de salud mencionado al comienzo. Los psicólogos clínicos deberán estar considerados en el Capitulo II, que hace referencia en sus distintos articulados, a la clasificación del personal, de la siguiente forma:

Dentro del Articulo 6, que ordena la clasificación por el nivel de titulación, en el Grupo Primero, que incluye los títulos de Licenciado, Ingeniero, Arquitecto o equivalentes.

Dentro del Articulo 7, que ordena la clasificación de la función desarrollada, como facultativos sanitarios. Licenciados Universitarios en posesión de un titulo de especialista.

Dentro del articulo 8, que ordena la clasificación por el tipo de nombramiento, dependerá de la situación administrativa de cada profesional.

El resto de los capítulos son de aplicación común para todo el personal estatutario, incluidos los psicólogos clínicos. 